\title{
EFFECT OF ORAL HEALTH EDUCATIONAL PROGRAM ON AWARENESS AND ORAL HEALTH STATUS OF CHILDREN WITH INSULIN DEPENDENT DIABETES MELLITUS A RANDOMIZED CLINICAL TRIAL
}

\author{
Samar Ali Zein El Abdeen Haikal ${ }^{*}$, Fatma Ahmed Hamdy El Shehaby ${ }^{* *}$ \\ and Sara Ahmed Mahmoud ${ }^{* * *}$
}

\begin{abstract}
Background: Diabetes Mellitus is one of the most common chronic diseases in children, plays a crucial role in the pathogenesis of periodontitis. Oral health education is a powerful tool in improving the oral hygiene knowledge and gingival health.
\end{abstract}

Objective: Assess the effect of oral health educational program on the oral health awareness and oral health status of Type 1 Diabetes Mellitus children in Cairo, Egypt.

Patients and methods: 44 Type 1 Diabetes Mellitus Egyptian children aged 6-14 years old were enrolled. The eligible children were randomized using random number generation computer program into two groups, Intervention group $(n=22)$ and Control group $(n=22)$. Manual scaling and the oral health educational program were conducted for the intervention group. Follow up visits were every month for three successive months, to collect OHI-s for both groups.

Results: Average knowledge of intervention group was $72.2 \%$ before the program, which became $80.9 \%$ after it. The median OHI-s decreased statistically significant $(p=.028)$ from baseline (1.94) to the fourth visit (1.42) in the intervention group.

Conclusion: The oral health knowledge among Type 1 Diabetes Mellitus children and their parents was satisfactory but their knowledge about the daily practice was deficient. Significant improvement in $\mathrm{OHI}-\mathrm{s}$ records after implementation of the program.

KEYWORDS: Awareness, Diabetes, Educational Program, OHI-s, Oral Health.

\footnotetext{
* Faculty of Dentistry, Ain Shams University, Cairo, Egypt

** Professor of Pediatric Dentistry \& Dental Public Health Faculty of Dentistry, Cairo University, Cairo, Egypt *** Associate Professor of Pediatric Dentistry \& Dental Public Health Faculty of Dentistry, Cairo University, Cairo, Egypt
} 


\section{INTRODUCTION}

Health promoting activities, such as oral health promotion, preventive advice and screening, are seldom integrated with dental care. Improvements in oral health resulting from oral health promotion activities are more sustainable and can reduce inequalities through action directed at the underlying determinants of oral health. There is a good evidence that prevention and oral health education approaches are more effective, than standard dental care ${ }^{1}$.

Diabetes mellitus is one of the most common chronic diseases in children and adolescents. T1DM represents only 5 to $10 \%$ of all diagnosed diabetes cases; however, it is the leading form of diabetes in children of all ages and accounts for almost all diabetes in children younger than 10 years old ${ }^{2}$.

Diabetes Mellitus plays a crucial role in the pathogenesis of periodontitis. The etiology for gingivitis is bacterial, which accumulates on the teeth. The oral cavity serves as a continuous source of infectious agents that could further worsen the diabetic status of the patient and serve as an important risk factor deterioration of diabetes mellitus ${ }^{3,4}$.

The International Diabetes Federation (IDF) (2017) $^{5}$ listed Egypt among the world's top 10 countries in the number of patients with diabetes. It is expected that the number of patients with diabetes in the Middle East and North Africa (MENA) region to grow by $96 \%$ from year 2013 to 2035 .

Plaque control is the process which involves dental plaque biofilm active removal, is a responsibility undertaken personally by individuals Today, most people exercise some measures of oral hygiene especially tooth brushing however very few people brush their teeth well enough at time that all plaque is removed. Individuals who perform effective oral hygiene routines directly affects the quality of dental plaque disruption and causes lower percentage of sites with dental plaque ${ }^{6,7}$.
This study was carried out to assess the effect of oral health educational program on the oral health awareness and status of Type 1 Diabetes Mellitus children attending in the Endocrine department in $\mathrm{Abu} \mathrm{El}$ Resh Hospital- Monira Hospital, Cairo, Egypt.

\section{METHODOLOGY}

\section{Subjects}

The study was carried out on Type 1 Diabetes Mellitus children enrolled from outpatient's clinic of Endocrine Department in Abu El Resh HospitalMonira Hospital.

\section{Ethical Aspects}

Ethical committee for research had approved the study protocol. This was done to make sure there were no harm to both the participants and the investigator with ethical approval number: 1766.

\section{Evidence Committee}

Evidence committee approval was obtained after protocol review.

\section{Eligibility criteria:}

\section{Inclusion criteria:}

1. Children aged 6-14 years old from both gender

2. Type 1 Diabetes Mellitus children (T1DM)

\section{Exclusion criteria:}

1. Children with any other systemic disease or other medications

2. Children undergoing orthodontic treatment

3. Parents unable to give informed consent

\section{Sample Size Determination}

Based on previous studies by Lee et al. (2009) ${ }^{8}$ and Gujjar et al. (2011) ${ }^{9}$, the oral hygiene and gingival health index within each subject group was normally distributed with the standard deviation one. A large effect size was expected $\mathrm{d}=1$ we needed study 17 subjects in each group. The type 1 error probability associated with the test of null 
hypothesis was 0.05 . This number was increased to 22 in each group to compensate the possible losses during the follow up.

The sample size was calculated by SPSS program.

\section{Randomization}

In Monira Hospital, Endocrine Department, Eligible diabetic children were chosen according to the inclusion and exclusion criteria, and then randomized by random number generation computer program into two groups.

\section{Blinding}

The study was not blinded as the manual scaling and the oral health program was done by the investigator, and the participants also knew they would receive manual scaling as the needed pre-operative precautions to be done as measuring their blood sugar level, taking their insulin shot and breakfast before starting the scaling.

\section{Study Groups}

\section{- Intervention Group}

This group included 22 children; they had manual scaling and received oral health educational program, by powerpoint presentation on Laptop, live demonstration of tooth brushing (Modified Bass Technique) on a jaw model and a poster designed by Egyptian Society for Pediatric Dentistry and Children with Special Needs was used to explain the causes of tooth decay development.

\section{- Control Group}

This group included 22 children; they did not receive manual scaling or oral health educational program.

\section{- Diagnostic procedure}

\section{Baseline Examination of Intervention and Control Groups}

- A consent explaining the aim and steps of the study was signed from the parent or caregiver of every participant.
- A modified Patient's diagnostic chart, of the Department of Pediatric Dentistry and Dental Public Health was filled, including patient's personal data (name, age, gender, address, telephone number), past medical, dental history and last record of Glycosylated Hemoglobin (HbA1c).

- Oral Hygiene Index simplified score (OHI-s) ${ }^{10}$ was calculated from participants of both groups.

\section{Procedure to Examine Oral Health Awareness}

- A modified questionnaire ${ }^{11,12}$ was designed to evaluate their knowledge, attitude and behavior regarding their oral health and dental treatment was given to the candidate's parents. Assessment of participants' knowledge regarding tooth brushing routine, effect of tooth brushing, the meaning of healthy gum, dental plaque and its effect.

- It was modified by adding question regarding their knowledge about the relation between oral health and T1DM.

- The original questionnaire was written in English and had been translated into Arabic. The Arabic form was submitted to the parents of both groups' participants.

- Participants of both groups had answered the questionnaire at the baseline.

\section{Procedure to Record Oral Hygiene Condition}

- Each participant was examined to assess their oral hygiene condition using Oral Hygiene Index simplified (OHI-s) ${ }^{10}$.

- The OHI-s has two components, the Debris Index (DI) and the Calculus Index (CI). Each of these indices is based on numerical determination representing the amount of debris or calculus found on the pre-selected tooth surfaces.

- Teeth selection: The OHI-s assesses 6 specific teeth, 1 tooth from each sextant. The number of surfaces: only 6 surfaces are used in the OHI-s.

- The teeth and surfaces which were examined are: The Buccal surfaces of maxillary right and left first molars, the Labial surfaces of maxillary 
right central incisor, the Labial surface of mandibular left incisor and the lingual surfaces of mandibular right and left first molars.

- Debris Index $(\mathrm{DI})=$ total of surface scores/ no. of surfaces

- Calculus Index $(\mathrm{CI})=$ total of surface scores/ no. of surfaces

- $\quad$ Oral Hygiene Index simplified $(\mathrm{OHI}-\mathrm{s})=$ Debris Index (DI) + Calculus Index (CI).

- The OHI-s ranges from 0 to 6 .

\section{Intervention group}

In the dental clinic of The Social and Preventive Medical Center, manual scaling was done using manual Pakistani scaler, made in Pakistan. Oral health educational program was conducted via power-point presentation on laptop was given to the children and their caregivers. Tooth decay and cariogenic diet were clarified through a poster. Demonstration of the parts of oral cavity, the effects of bad oral hygiene, the effect of diabetes on their oral health and of the proper technique of tooth brushing (Modified Bass Technique) using jaw model and toothbrush by the investigator. The children were asked to brush their teeth twice daily. Each child was given a new toothbrush and toothpaste at the beginning of the study.

\section{In both study groups:}

There were three follow-up examinations done after one month, two months and three months for assessing Oral Hygiene Index simplified (OHI-s) recorded in the diagnosis sheet. At the end of the study, the final questionnaire was submitted to the parents to assess the changes in their knowledge and awareness about oral health.

\section{Outcome:}

- This study was conducted to evaluate the oral health awareness of diabetic children's parents, as primary outcome, which was evaluated by a Questionnaire $^{11,12}$ which are binary units. Oral hygiene status was evaluated, as secondary outcome, which was evaluated by Oral Hygiene Index simplified $(\mathrm{OHI}-\mathrm{s}=\mathrm{DI}+\mathrm{CI})^{10}$ which is a numerical score.

\section{RESULTS}

\section{Oral Health Knowledge of Parents in Group A:}

Based on the answers for oral health related questions of the submitted oral health awareness questionnaires, answers showed that $72.2 \%$ is the average of knowledge of parents of group A participants before the oral health educational program, which became $80.9 \%$ after the program in the fourth visit, as presented in Table 1.

The difference between before and after the program was not statistically significant $(\mathrm{p}=0.99)$, as shown in Table 1.

TABLE (1) Oral Health Knowledge Improvement in Group A (Chi square test)

\begin{tabular}{|c|c|c|c|}
\hline Oral health question & $\begin{array}{l}\text { Before } \\
\text { program }\end{array}$ & $\begin{array}{c}\text { After } \\
\text { program }\end{array}$ & $\mathrm{P}$ \\
\hline Does diabetes affect gum health? & $60.0 \%$ & $66.7 \%$ & \multirow{9}{*}{$\begin{array}{l}\Omega \\
\text { z } \\
\text { aे }\end{array}$} \\
\hline Are healthy gums light pink in color? & $82.4 \%$ & $83.3 \%$ & \\
\hline Is bleeding gum a healthy gum? & $15.8 \%$ & $33.3 \%$ & \\
\hline $\begin{array}{l}\text { Does tooth brushing protect from } \\
\text { bleeding gums? }\end{array}$ & $94.7 \%$ & $100.0 \%$ & \\
\hline $\begin{array}{l}\text { Does plaque mean soft derbies of } \\
\text { food remnants on the tooth? }\end{array}$ & $82.4 \%$ & $83.3 \%$ & \\
\hline $\begin{array}{l}\text { Does tooth plaque lead to gum } \\
\text { inflammation? }\end{array}$ & $93.3 \%$ & $100.0 \%$ & \\
\hline $\begin{array}{l}\text { Is plaque cleaned by tooth } \\
\text { brushing? }\end{array}$ & $76.5 \%$ & $100.0 \%$ & \\
\hline Average & $72.2 \%$ & $80.9 \%$ & \\
\hline Difference & $8.79 \%$ & & \\
\hline
\end{tabular}

Significance level $P<0.05$, *significant, NS=non-significant 


\section{Tooth Brushing Habits Questions}

Before, $36.4 \%$ of group A brushed their teeth with $4.5 \%$ brushed twice daily and $36.4 \%$ of group B brushed their teeth with $14.3 \%$ brushed twice daily, as shown in Table 2.

TABLE (2): The results for the response (YES) in the study groups parents' answers to the baseline oral health awareness questionnaire:

\begin{tabular}{|l|c|c|}
\hline Tooth brushing habits question & Group A & Group B \\
\hline Does your child brush his/her teeth? & $36.4 \%$ & $36.4 \%$ \\
\hline Does he/she brush twice daily? & $4.5 \%$ & $14.3 \%$ \\
\hline
\end{tabular}

After, $83.3 \%$ of group A brushed their teeth with $66.7 \%$ brushed twice daily and $75.0 \%$ of group B brushed their teeth with $37.5 \%$ brushed twice daily, as shown in Table 3.
TABLE (3) results for the response (YES) in the study groups parents' answers to the baseline oral health awareness questionnaire:

\begin{tabular}{lcc}
\hline Question & $\begin{array}{c}\text { Group } \\
\text { A }\end{array}$ & Group B \\
\hline Does your child brush his/her teeth? & $83.3 \%$ & $75.0 \%$ \\
Does he/she brush twice daily? & $66.7 \%$ & $37.5 \%$ \\
\hline
\end{tabular}

\section{Oral Hygiene Index simplified (OHI-s):}

\section{Comparison between the study groups:}

\section{As shown in Table 4,}

At baseline, in group A, OHI-s median of 1.94, in comparison to 1.65 in group B.

In second visit, in group A, OHI-s median of 1.50 , in comparison to 1.70 in group $\mathrm{B}$.

In third visit, in group A, OHI-s median of 1.33, in comparison to 1.92 in group B.

In fourth visit, in group A, OHI-s median of 1.42, in comparison to 2.17 in group B.

TABLE (4): Descriptive statistics; mean, standard deviation and median of Oral Hygiene Index simplified with comparison between the study groups (Mann Whitney U test).

\begin{tabular}{|c|c|c|c|c|c|c|c|c|c|}
\hline \multicolumn{5}{|c|}{ Group Statistics } & \multicolumn{4}{|c|}{ Difference } & \multirow[b]{2}{*}{$P$} \\
\hline \multicolumn{2}{|c|}{ Groups } & Mean & Std. & Median & Mean & Std. Error & 95\% C.I. & 95\% C.I. & \\
\hline \multirow{2}{*}{ Baseline } & Group A & 2.00 & .50 & 1.94 & \multirow{2}{*}{.29} & \multirow{2}{*}{.17} & \multirow{2}{*}{-.05} & \multirow{2}{*}{.64} & \multirow{2}{*}{$.077 \mathrm{NS}$} \\
\hline & Group B & 1.71 & .62 & 1.65 & & & & & \\
\hline \multirow{2}{*}{1 month } & Group A & 1.54 & .74 & 1.50 & \multirow{2}{*}{-.30} & \multirow{2}{*}{.25} & \multirow{2}{*}{-.82} & \multirow{2}{*}{.22} & \multirow{2}{*}{$.183 \mathrm{NS}$} \\
\hline & Group B & 1.84 & .62 & 1.70 & & & & & \\
\hline \multirow{2}{*}{2 months } & Group A & 1.48 & .34 & 1.33 & \multirow{2}{*}{-.33} & \multirow{2}{*}{.21} & \multirow{2}{*}{-.77} & \multirow{2}{*}{.11} & \multirow{2}{*}{$.160 \mathrm{NS}$} \\
\hline & Group B & 1.81 & .57 & 1.92 & & & & & \\
\hline \multirow{2}{*}{3 months } & Group A & 1.37 & .58 & 1.42 & \multirow{2}{*}{-.76} & \multirow{2}{*}{.29} & \multirow{2}{*}{-1.41} & \multirow{2}{*}{-.11} & \multirow{2}{*}{$.028 *$} \\
\hline & Group B & 2.13 & .47 & 2.17 & & & & & \\
\hline
\end{tabular}

Significance level $P<0.05$, * significant, NS=non-significant 


\section{Comparison within the same group}

In group $\mathbf{A}$, the median OHI-s gradually decreased from 1.94 at the baseline respectively to 1.50 then 1.33 at the $3^{\text {rd }}$ follow-up visit, then showed an increase from the $3^{\text {rd }}$ visit to the $4^{\text {th }}$ visit to reach 1.42. Friedman test revealed that the change by time was not statistically significant $(p=.055)$.

In group $\mathbf{B}$, the median OHI-s gradually increased from 1.65 at the baseline respectively to 1.70 then 1.92 then 2.17 at the $4^{\text {th }}$ follow-up visits. Friedman test revealed that the change by time was not statistically significant $(p=.074)$.

1. Age: Age in the study sample ranged from 6 to 12 years. The mean age of patients in group $\mathrm{A}$ was $9.57 \pm 1.84$, while the mean age for patients in group B was $9.11 \pm 1.80$.

2. Gender percentage: In group A, 15 (68.2\%) females and $7(31.8 \%)$ males, in comparison to $10(45.5 \%)$ females and $12(54.5 \%)$ males in group B.

3. Glycosylated Hemoglobin (HbA1c): the mean HbA1c value of patients in group A was 8.75 \pm 2.09 , while the mean $\mathrm{HbA} 1 \mathrm{c}$ value for group B was $9.46 \pm 2.32$.

\section{DISCUSSION}

The current study was planned to educate Type 1 Diabetes Mellitus children the basic skills of tooth brushing and importance of oral hygiene and raising awareness regarding oral health and diabetes.

The current study was carried out at Monira Hospital and Social and Preventive Medical Center in Cairo Governorate, Egypt, for a better access to diabetic children. Forty-four Type 1 Diabetic children were included in the study, age from 6-14 years old. The whole sample was divided into two groups: group $\mathrm{A}(\mathrm{n}=22$ children), received manual scaling and dental educational program by power point presentation and demonstration on jaw model and poster. Group B ( $\mathrm{n}=22$ children) didn't have scaling or the educational program.
There was another difference between this study and the similar studies was in the manual scaling done in the beginning of the study in group A to ensure a clean, plaque and calculus free tooth surfaces for comparing the effectiveness of oral educational health program on the oral hygiene of the participants so professional gingival scaling was the most required periodontal treatment for diabetic children as suggested by Arheiam \& Omar ${ }^{13}$. While the control group B children didn't have manual scaling, so no interference was done by the investigator to illustrate the difference in plaque accumulation presented in the oral hygiene records and to evaluate the actual state of the oral hygiene in diabetic children.

Group A, at baseline, almost $60 \%$ of the participants' parents knew the effect of diabetes on the gum health; this indicates awareness about relation of diabetes and oral heath, which comes in agreement with Yuen et al. ${ }^{14}$ and Kamath et al. ${ }^{15}$. The majority of them also were aware of signs of gingival disease like bleeding during brushing and color of healthy gingiva which is not in accordance with Ismaeil \& $\mathbf{A l i}^{16}$. Almost $94 \%$ of them knew that brushing protects gingiva health and almost $80 \%$ knew that brushing also cleans plaque. Not statistically significant increase in their knowledge, as shown in Table 1.

There was a statistically significant increase in the tooth brushing habits in group A; as $36 \%$ of the children brushed their teeth, while only $4.5 \%$ of them brushed their teeth twice daily before the educational program; this is unlike the findings of Kamath et al. ${ }^{15}$. After receiving the program, $83.3 \%$ of the children brushed their teeth, while $66.5 \%$ brushed their teeth twice daily. There was a decrease in their OHI-s score (-0.52) through the follow up visits, which explains that after the program, $62.2 \%$ of the children brushed their teeth effectively and they also became more aware of importance of tooth brushing and were motivated for tooth brushing routine, as shown in Table $2 \&$ Table 3. This comes in agreement with de Farias et al. ${ }^{17}$. 
In this study, as presented in Table 4, the median of oral hygiene index simplified in the intervention group (group A) decreased from 1.94 at the baseline to 1.42 at the fourth visit which means that the educational program enhanced improvement in the oral health status. Although, it gradually decreased from the baseline to each of second and third followup visits, it then showed an increase from the third (1.33) to the fourth visit (1.42), which could happen as children might have ignored their oral health habits for a while as they lose excitement easily. This decrease was not statistically significant.

Table 4 showed that there was statistically significant difference in the median of OHI-s score between the study groups in the fourth visit; which indicates the effect of oral health program and the efficiency of the Modified Bass Brushing method which came in consistent with Patil et al. ${ }^{18}$.

Whereas the control group (group B) that didn't receive educational program or have manual scaling, had gradually increased from 1.65 at the baseline to reach 2.17 at the fourth visit and this increase was not statistically significant, as shown in Table 4. Which comes in agreement with López del Valle \& Ocasio-López ${ }^{19}$ and Sohn \& Rowe ${ }^{20}$ who reported that T1DM children has higher plaque accumulation.

Three follow up examinations were assessed after one month, two months and three months using Oral Hygiene Index simplified (OHI-s) for evaluating the effect of the dental educational program on the oral health status of the diabetic children. The duration of this study meets the recommendation for the characteristics of community-based oral health program including tooth brushing program time should be extended for one month, by Petersen $\boldsymbol{\&}$ Kwan ${ }^{21,22,23}$. The study was extended into 3 months to meet the glycemic control measurement by the glycosylated hemoglobin.

The difference was not statistically significant between mean age values for both groups as well as no significant difference between both groups for gender. That indicates the homogeneity of the study participants. In addition to, there was no statistically significant difference in the mean value of the glycosylated hemoglobin between both groups. No statistically significant difference in the median of oral hygiene index simplified score between both groups at the baseline, as presented in Table 4, which indicates the good randomization process for achieving equal baseline characteristics of participants of both intervention and control groups.

\section{CONCLUSIONS}

- Although, the oral health knowledge among Type 1 Diabetes Mellitus children and parents was satisfactory while their knowledge about the daily practice was deficient.

- Oral health Educational program made a significant improvement in the tooth brushing habit and knowledge attitude.

- There is statistically significant difference in the median of OHI-s score between the study groups in the fourth visit.

- Perfect positive relation between the increase in the tooth brushing habit and improvement in the oral hygiene.

- Children got easily motivated for brushing by simple demonstration of brushing technique and got encouraged when they took the toothbrush and toothpaste.

\section{RECOMMENDATIONS}

- Similar study can be applied with different socioeconomic levels of T1DM children and other systemic diseases.

- More studies are required to compare the oral health status between diabetic and non-diabetic children.

- A survey study is needed to detect the amount of diabetic patients that received oral health awareness programs. 


\section{LIMITATION}

- Few patients showed non-compliance to the three follow up visits, therefore there was 10 dropouts in this study.

- Due to nature of the disease, some participants whose insulin was not in the normal level couldn't have the manual scaling in the baseline visit, and therefore it was postponed until insulin level was normal.

Conflicts of interest: No conflicts of interest were encountered.

\section{ACKNOWLEDGEMENT}

The authors are grateful for the patients without whom this study would not have been done.

\section{REFERENCES}

1. Carvalho, J. C., Rebelo, M. A. \& M. V. Vettore. The relationship between oral health education and quality of life in adolescents. International Journal of Paediatric Dentistry. 2013; 23: 286-296.

2. Kamath, D. G., Nayak, S. U., Pai, K. K. \& Shenoy, R. Knowledge and Awareness of Oral Health among Diabetic Patients - a cross-sectional study from Mangalore City. International Journal of Diabetes in Developing Countries. 2015; 35(2): 71-75.

3. Gurav, A. \& Jadhav, V. Periodontitis and risk of diabetes mellitus. Journal of Diabetes. 2011;3(1): 21-28.

4. Gurav, A. N. Management of diabolical diabetes mellitus and periodontitis nexus: Are we doing enough? World Journal of Diabetes. 2016; 7(4): 50-66.

5. International Diabetes Federation, IDF Diabetes Atlas Eight Edition, 2017. [Report]

6. Kolawole, K. A., Oziegbe, E. O. \& Bamise, C. T. Oral hygiene measures and the periodontal status of school children. International Journal of Dental Hygiene. 2011; 9: $143-148$

7. De David, S. C., Mário, T. G., De Freitas, G. C., Kantorski, K. Z., Wikesjö, U. M. E. \& Moreira, C. H. C. Correlation between plaque control and gingival health using short and extended oral hygiene intervals. Clinical Oral Investigations. 2018; 22(7): 2593-2597.
8. Lee, H., Choi, S., Won, K., Merchant, A. T., Song, K., Jeong, S., Lee, S. \& Choi, Y. The effect of intensive oral hygiene care on gingivitis and periodontal destruction in type 2 diabetic patients. Yonsei Medical Journal. 2009; 50(4): 529-536.

9. Gujjar, K. R., Khadija, H., Suleiman, M. O. \& Amith, H. V. Gingival health status of 2 to 15 -year-old Benghazi children with type-I diabetes mellitus. Journal of dentistry for children (Chicago). 2011; 78(2): 96-101.

10. Greene, J. C. \& Vermillion, J. R. THE SIMPLIFIED ORAL HYGIENE INDEX. The Journal of American Dental Association. 1964; 8(1): 7-13. [Newspaper Article]

11. Peterson, P. E., Aleksejuniene, J., Christensen, L. B, Eriksen, H. M. \& Kalo, I. Oral health behavior and attitudes of adults in Lithuania. Acta Odontol Scand. 2000; 58(6): 243-248.

12. Stenberg, P., Hakansson, J. \& Akerman, S. Attitudes to dental health and care among 20 to 25 -year-old Swedes: results from a questionnaire. Acta Odontol Scand. 2000; 58: 102-106.

13. Arheiam, A. \& Omar, S. Dental caries experience and periodontal treatment needs of 10- to 15-year old children with type 1 diabetes mellitus. International Dental Journal. 2014; 64(3): 150-154.

14. Yuen, H. K., Wolf, B. J., Bandyopadhyay, D., Magruder, K. M., Salinas, C. F. \& London, S. D. Oral health knowledge and behavior among adults with diabetes. Diabetes Research and Clinical Practice. 2009; 86(3): 239-246.

15. Kamath, D. G., Nayak, S. U., Pai, K. K. \& Shenoy, R. Knowledge and Awareness of Oral Health among Diabetic Patients - a cross-sectional study from Mangalore City. International Journal of Diabetes in Developing Countries. 2015; 35(2): 71-75.

16. Ismaeil, F. \& Ali, N. Diabetic Patients Knowledge, Attitude and Practice toward Oral Health. Journal of Education and Practice. 2013; 4(20): 19-25.

17. De Farias, I. A., De Ara $\tilde{A}^{\circ}$ jo Souza, G. C. \& Ferreira, M. Ã. F. A Health Education Program for Brazilian Public Schoolchildren: The Effects on Dental Health Practice and Oral Health Awareness. Journal of Public Health Dentistry. 2009; 69(4): 225-230.

18. Patil, S. P., Patil, P. B. \& Kashetty, M. V. Effectiveness of different tooth brushing techniques on the removal of dental plaque in 6-8 year old children of Gulbarga. Journal 
of International Society of Preventive \& Community Dentistry. 2014; 4(2): 113-116.

19. López del Valle, L. M. \& Ocasio-López, C. Comparing the oral health status of diabetic and non-diabetic children from Puerto Rico: a case-control pilot study. Puerto Rico Health Sciences Journal. 2011; 30(3): 123-127.

20. Sohn, H. A. \& Rowe, D. J. Oral Health Knowledge, Attitudes and Behaviors of Parents of Children with Diabetes Compared to Those of Parents of Children without Diabetes. The Journal of Dental Hygiene. 2015; 89(3): 170-179.

21. Petersen, P. E. \& Kwan, S. Evaluation of communitybased oral health promotion and oral disease prevention-
WHO recommendations for improved evidence in public health practice. 2004; 21(S1): 319-329.

22. M Ghaffari, S Rakhshanderou, A Ramezankhani, M Noroozi , B Armoon. Oral Health Education and Promotion Programmes: Meta-Analysis of 17-Year Intervention. International Journal of Dental Hygiene. 2018;16(1): 59-67.

23. Mahmood Karimy, Peter Higgs, Shaghaygh Solayman Abadi, Bahram Armoon, Marzieh Araban, Mohammad Reza Rouhani, Fereshteh Zamani-Alavijeh. Oral health behavior among school children aged 11-13 years in Saveh, Iran: an evaluation of a theory-driven intervention. BMC Pediatr. 2020; 20: 476. 